\title{
An application of fuzzy AHP for ranking human resources development indices
}

\author{
Mehdi Paktinat ${ }^{\mathrm{a}}$ and Abolfazl Danaei ${ }^{\mathrm{b}^{*}}$
}

${ }^{a}$ Department of Management College of Management, Semnan Science and Research Branch, Islamic Azad university, Semnan, Iran ${ }^{b}$ Department of Management, College of Management, Semnan Branch, Islamic Azad university, Semnan, Iran

\section{H R O I C L E A B S T R A C T}

Article history:

Received 5 January 2014

Received in revised format 8 March 2014

Accepted 14 March 2014

Available online

16 March 2014

Keywords:

HDI

Human development index

Fuzzy AHP

\begin{abstract}
The Human Development Index (HDI) is a composite statistic of life expectancy, education, and income indices, which is implemented to rank countries into different items of human development including life expectancy, education, living standards. This paper uses fuzzy analytical hierarchy process (AHP) to rank five influencing factors including income, culture, healthcare, knowledge and civil rights in Iran. Using a questionnaire in linguistic form, the study asks some experts to make judgment about the relative importance of each pair of five items and it ranks them based on fuzzy AHP technique. The results indicate that income is number priority followed by knowledge, culture, civil rights and healthcare affairs.
\end{abstract}

\section{Introduction}

The Human Development Index (HDI) is a composite statistic of life expectancy, education, and income indices, which is implemented to rank countries into different items of human development including life expectancy, education, living standards. A country's overall index indicates the fact that various groups within the country may have totally different levels of human development. Disaggregated HDIs are computed by using the data for the HDI figures pertaining to each of the separate groups; treating each group as if it were a separate country. Such groups may be described relative to income, geographical or administrative regions, urban/rural residence, gender and ethnicity. HDI is calculated based on the three mentioned dimensions, which are calibrated and combined to generate an HDI score between zero and one. Normally, countries are categorized into four human development categories or quartiles including very high, high, medium and low. When a country is grouped in the very high group, HDI is in the top quartile, if its HDI is in percentiles 51-75

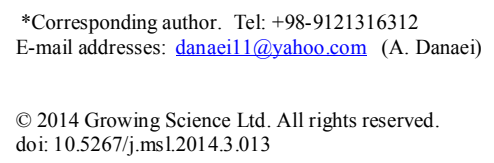


the country is in the high group, in the medium group if its HDI is in percentiles 26-50, and finally in the low group if its HDI is in the bottom quartile.

The first HDI introduced a new way of measuring development by integrating indicators of life expectancy, educational attainment and income into HDI. The breakthrough for the HDI was the creation of a single statistics, which is a reference for both social and economic development. The HDI sets a minimum and a maximum for each dimension, called goalposts, and then demonstrates where each country stands in association with these goalposts, expressed as a value between 0 and 1 .

The education part of the HDI is computed by mean of years of schooling for adults aged 25 years and expected years of schooling for children of school entering age. The average years of schooling is calculated based on educational attainment data from censuses and surveys available in the UNESCO Institute for Statistics database and Barro and Lee (2010, 2013) method. Expected years of schooling estimates are based on enrolment by age at all levels of education and population of official school age for each level of education. The indicators are normalized based on a minimum value of zero and maximum values are set to the actual observed maximum value of mean years of schooling from the countries in the time series, 1980-2012, which is 13.3 years estimated for the United States in 2010.

The life expectancy at birth component of the HDI is normally measured based on a minimum value of 20 years and maximum value of 83.57 years and it is the observed maximum value of the indicators from the countries in the time series, 1980-2012. For the wealth component, the goalpost for minimum income is normally set to $\$ 100$ (PPP) and the maximum is set to $\$ 87,478$ (PPP), forecasted for Qatar in 2012. The decent standard of living component is computed by growth national income (GNI) per capita (PPP\$) instead of GDP per capita (PPP\$) The HDI applies the logarithm of income, to present the diminishing importance of income with increasing GNI. The scores for the three HDI dimension indices are combined into a composite index by applying geometric mean.

Noorbakhsh (1998) investigated a modified index for measuring HDI developed by the United Nations Development Programme (UNDP). The study discussed two groups of technical issues associated with the HDI for 1995 including components figures and those relevant to the structure of the index. Paul (1996) proposed another modified HDI, which complies with other studies that an increase in the value of a physical indicator at a higher level could represent a bigger achievement than an equal increase in its value at the lower level. The method also includes an infant survival rate, which plays essential role on development. The relative ranking of countries based on the modified index seems to be substantially different from that based on the traditional HDI. Ranis et al. (2000) investigated the connections between economic growth (EG) and human development (HD) form two chains.

According to Ravallion (2012), The 20th Human Development Report introduced a new version of its HDI, which aggregates country-level attainments in life expectancy, schooling and income. The main change was to relax the past assumption of perfect substitutability between its components. Most users may not understand that the new HDI has also tremendously reduced its implicit weight on longevity in poor countries, relative to rich ones. By contrast, the new HDI's valuations of extra schooling are now very high-many times the economic returns.

\section{The proposed}

In this paper, we present an implementation of analytical hierarchy process (AHP) (Saaty, 1988) to rank the relative importance of five influencing factors including income, culture, healthcare, knowledge and civil rights in Iran. Fig. 1 demonstrates the structure of the proposed study. 


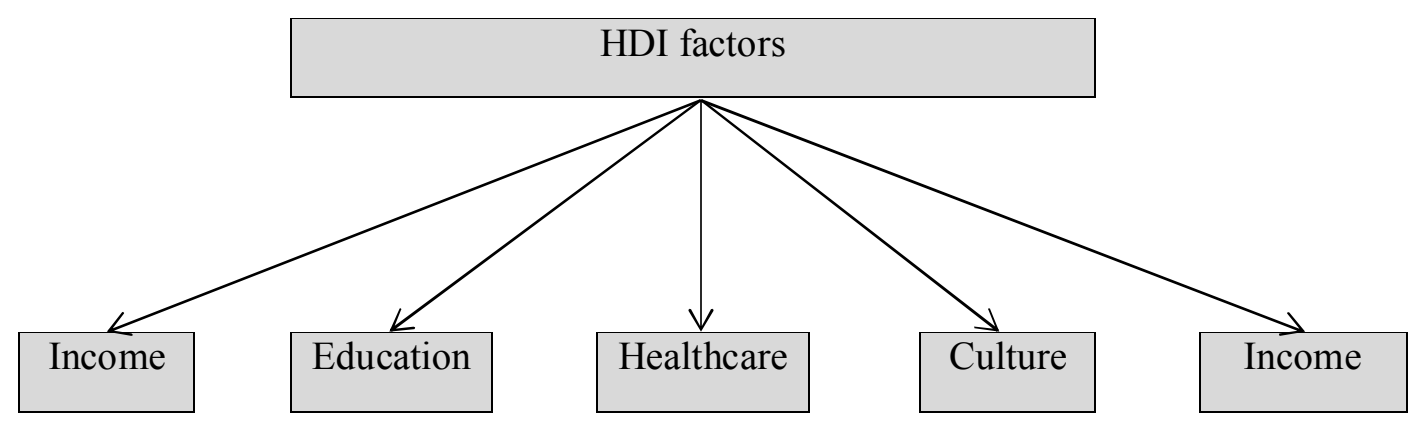

Fig. 1. The hierarchy of the proposed study

As we can observe from the results of Fig. 1, all five figures maintain the same level of relative importance. Traditional AHP method has several advantages since decision maker only thinks about comparing one item against the other one at the same time but decision maker may not certain about the numbers, he/she expresses. Therefore, we may use linguistic terms to make comparison. Chang (1996) is believed to be the first who introduced fuzzy AHP and it has widely been used for various applications. Bozbura et al. (2007), for instance, used fuzzy AHP for prioritization of human capital measurement indicators. Table 1 shows the linguistic terms used in this paper for the proposed study.

Table 1

The linguistic terms

\begin{tabular}{ccc}
\hline & \multicolumn{2}{c}{ Fuzzy AHP Scale } \\
\cline { 2 - 3 } Linguistic variables & TFS & Reciprocal TFS \\
\hline Equally Preferred & $(1,1,1)$ & $(1,1,1)$ \\
Equally to Moderately Preferred & $(1,2,3)$ & $(1 / 3,1 / 2,1)$ \\
Moderately Preferred & $(2,3,4)$ & $(1 / 4,1 / 3,1 / 2)$ \\
Moderately to Strongly Preferred & $(3,4,5)$ & $(1 / 5,1 / 4,1 / 3)$ \\
Strongly Preferred & $(4,5,6)$ & $(1 / 7,1 / 6,1 / 4)$ \\
Strongly to Very Strongly Preferred & $(5,6,7)$ & $(1 / 8,1 / 7,1 / 6)$ \\
Very Strongly Preferred & $(6,7,8)$ & $(1 / 9,1 / 8,1 / 7)$ \\
Very Strongly to Extremely Preferred & $(7,8,9)$ & $(1 / 9,1 / 9,1 / 8)$ \\
Extremely Preferred & $(8,9,9)$ & \\
\hline
\end{tabular}

The proposed study converts all linguistic judgments into triangular numbers and combines them by taking geometric mean. Table 2 shows lower, middle and upper numbers.

Table 2

The summary of lower, middle and upper numbers

\begin{tabular}{|c|c|c|c|c|c|c|c|c|c|c|c|c|c|c|c|c|c|}
\hline & \multicolumn{5}{|c|}{ Lower } & \multicolumn{6}{|c|}{ Middle } & \multicolumn{6}{|c|}{ Upper } \\
\hline & 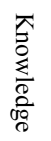 & $\frac{尺}{\Xi_{\overparen{\Xi}}}$ & $\begin{array}{l}\bar{E} \\
\text { } \\
\text { छ }\end{array}$ & @. & 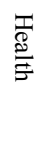 & & 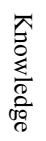 & $\underset{\overparen{\Xi}}{\stackrel{\Xi}{E}}$ & $\begin{array}{l}\vec{\Xi} \\
\hat{ٍ} \\
\bar{\delta}\end{array}$ & $\stackrel{\text { S }}{\vdots}$ & $\frac{\sqrt[\mathbb{P}]{\mathscr{巳}}}{\stackrel{\mathscr{E}}{E}}$ & & 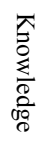 & 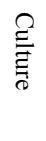 & 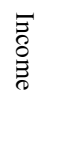 & $\stackrel{\Omega}{\Xi}$ & 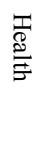 \\
\hline Knowledge & 1 & 2 & 0.25 & 4 & 7 & Knowledge & 1 & 3 & 0.33 & 5 & 8 & Knowledge & 1 & 4 & 0.5 & 6 & 9 \\
\hline Culture & & 1 & 0.25 & 4 & 6 & Culture & & 1 & 0.33 & 5 & 7 & Culture & & 1 & 0.5 & 6 & 8 \\
\hline Income & & & 1 & 3 & 9 & Income & & & 1 & 4 & 9 & Income & & & 1 & 5 & 9 \\
\hline Civil & & & & 1 & 1 & Civil & & & & 1 & 2 & Civil & & & & 1 & 3 \\
\hline Health & & & & & 1 & Health & & & & & 1 & Health & & & & & 1 \\
\hline
\end{tabular}

Based on the data gathered from Table 2, we may now apply Chang (1996) method and the results are summarized in Table 3 as follows, 
Table 3

The summary of fuzzy AHP method

\begin{tabular}{lll}
\hline \multicolumn{1}{c}{ Variable } & Weight & Rank \\
\hline Knowledge & 0.2461 & 2 \\
Culture & 0.2325 & 3 \\
Income & 0.2479 & 1 \\
Civil rights & 0.1539 & 4 \\
Health & 0.1196 & 5 \\
\hline
\end{tabular}

\section{Conclusion}

In this paper, we have presented an empirical investigation to rank five well-known factors influencing HDI in Iran. The proposed study has applied fuzzy AHP method to rank the factors in terms and the results indicate that income is number priority followed by knowledge, culture, civil rights and healthcare affairs. The results of this survey could help politicians and economics setup appropriate actions for the development of country.

\section{Acknowledgement}

The authors would like to thank the anonymous referees for constructive comments on earlier version of this paper.

\section{References}

Barro, R., \& Lee, J. W. (2010). Educational attainment in the world: 1950-2010.NBER Working Paper, (15902).

Barro, R. J., \& Lee, J. W. (2013). A new data set of educational attainment in the world, 19502010. Journal of Development Economics, 104, 184-198.

Bozbura, F. T., Beskese, A., \& Kahraman, C. (2007). Prioritization of human capital measurement indicators using fuzzy AHP. Expert Systems with Applications, 32(4), 1100-1112.

Chang, D. Y. (1996). Applications of the extent analysis method on fuzzy AHP. European journal of operational research, 95(3), 649-655.

Noorbakhsh, F. (1998). A modified human development index. World Development, 26(3), 517-528.

Paul, S. (1996). A modified human development index and international comparison. Applied Economics Letters, 3(10), 677-682.

Ranis, G., Stewart, F., \& Ramirez, A. (2000). Economic growth and human development. World Development, 28(2), 197-219.

Ravallion, M. (2012). Troubling tradeoffs in the human development index. Journal of Development Economics, 99(2), 201-209.

Saaty, T. L. (1988). What is the analytic hierarchy process? (pp. 109-121). Springer Berlin Heidelberg. 